\title{
Statistical Analysis of Risk Factors of Drug Addiction of Youth in Debre Berhan Town, Ethiopia
}

\author{
Bezarede Mekonnen", Legesse Alamrie \\ Email address: \\ bezaredemekonnen70@gmail.com (B. Mekonnen), lege122129@gmail.com (L. Alamrie) \\ ${ }^{*}$ Corresponding author
}

Department of Statistics, College of Natural and Computational Science, Debre Berhan University, Debre Berhan, Ethiopia

\section{To cite this article:}

Bezarede Mekonnen, Legesse Alamrie. Statistical Analysis of Risk Factors of Drug Addiction of Youth in Debre Berhan Town, Ethiopia. American Journal of Theoretical and Applied Statistics. Vol. 9, No. 1, 2020, pp. 8-13. doi: 10.11648/j.ajtas.20200901.12

Received: October 7, 2019; Accepted: April 15, 2020; Published: April 23, 2020

\begin{abstract}
Drugs are damaging by their nature. These substances produce changes in behavior function by altering the chemistry of the brain. Once brain function is altered, a person experiences physical, psychological, and behavioral changes as a direct result. Changes in physical and psychological functioning cause damage to the mind, body, behavior and can harm the social relationships. According United Nations Office for Drug Control and Crime Prevention report, the use of substances such as alcohol, khat, and tobacco has become one of the rising major public health and socioeconomic problem worldwide. The main objective of this study is to identify the risk factors for drug addiction of youth in debre berhan town. In general, this study is expected to be useful for the parents, the youth themselves, government, nongovernmental organization, and city administration in providing primary information and assist the concerned bodies to come up with appropriate intervention strategies that can help to curb the drug problem. The data is primary and cross-sectional. Descriptive statistics and the binary logistic regression analysis is applied to examine the association between the binary outcome dependent variable and explanatory variables. The binary logistic model revealed that the numbers of youth those are addicted in the age group 20-25 are much greater than from the youth those are addicted in the age group 15-19 and 25-30, youths with family members who use drugs are more likely to be drug addicts, and also those who are orthodox religion followers are more likely to be addicted than Muslim, protestant and other religion follower, additionally youth who are single are more drug user than married, divorced and widowed.
\end{abstract}

Keywords: Drug Addiction, Alcohol, Khat, Tobacco and Binary Logistic Regression

\section{Introduction}

Humans have used drugs of one sort or another for thousands of years. Wine was used at least from the time of the early Egyptians; narcotics from 4000 B. C. and medicinal use of marijuana has been dated to 2737 B. C. in China. Since earliest time, herbs, roots, leaves and plants have been used to relieve pain and help control disease. However, some drugs synthesized out of these substances have been found to act on the brain and alter mood in ways that are not always socially approved, such as a feeling of euphoria (a "feeling of elation"), restlessness, nightmare, hallucinations and delusions [1].

According United Nations Office for Drug Control and Crime Prevention report, the use of substances such as alcohol, khat, and tobacco has become one of the rising major public health and socioeconomic problem worldwide. Today, Substance use and problems arising from it are increasing all over the world and currently together with HIV/AIDS epidemic, become one of the most threatening and challenging social and public health problems. There are an estimated 180 million drug users around the globe, equivalent to $3 \%$ of the global population or $4.2 \%$ of the population age 15 and above [2].

Drugs are damaging by their nature. These substances produce changes in behavior function by altering the chemistry of the brain. Once brain function is altered, a person experiences physical, psychological, and behavioral changes as a direct result. Changes in physical and psychological functioning cause damage to the mind, body, behavior and can harm the social relationships [3]. The extent to which these consequences may occur depends up 
on the drug used, the person using the drug, and circumstances under which the drug is used. People differ in their drug use, some people never experiment; some experiment and never use again. Others use drugs irregularly, whereas others develop addiction [4].

According to the United Nations Office report on the practice of substance abuse, the problem of substance abuse became worsen by complex psycho-social challenges such as unemployment, poverty, crime, unwanted pregnancy and sexual assault. Despite challenges, drug dealers have exerted a profound influence on young people to take substances so that once they become addicted, they further influence their friends into taking substances. As a result these problems have been overwhelming many families and communities across nations [5].

The use of alcohol during the teenage and young adulthood years is becoming a common phenomenon in many societies in Ethiopia. A study conducted by FRDE Drug Administration and Control authority in different part of Ethiopia also show that there is a prevalence of drug use by youths. The concern given by the government and nongovernmental organizations and understanding of the general community is limited, hence a number institutions providing services for young people suffering from substance use is inadequate and insufficient.

Drugs indiscriminately affect all people but the youth are the most vulnerable one. Drug during adolescence (16- 25 years) is common. On this particular age, adolescents become probing to try so many new things. The initial factor that seems to influence adolescents' experimentation with drug use seems to be curiosity.

The main objective this study is to identify the risk factors for drug addiction of youth in debreberhantown.

In general, this study is expected to be useful for the parents, the youth themselves, government, nongovernmental organization, and city administration in providing primary information and assist the concerned bodies to come up with appropriate intervention strategies that can help to curb the drug problem.

\section{Review of Related Litrature}

\section{DRUG}

In medicine, drug is any substance with potential to prevent or cure disease. In common usage, the term often refers to especially to psychoactive drugs, and often, even more specifically, to illicit drugs (Heroin, cocaine, cannabis). However, caffeine, tobacco, alcohol, and other substances in common non-medical use are also drugs [1].

The use of drugs/ substances is a result of the interactions between the individual, the substance and the environment.

Young people especially have particular characteristics that make them vulnerable to substance use. Some of the risk factors include: peer pressure, unemployment and redundancy, wanting to socialize, wanting to feel high, wanting to forget problems, wanting to establish independence from the family, the need to belong and to be accepted (e.g. smoking is a way of showing that one is mature), availability of substances, etc. [6].

\section{ALCOHOL}

The Risk factors for alcoholism fall into three categories: family history, ethnic background, and occupation or social milieu [7]. These three factors describe the social fabric of most people's lives. As such, it is difficult to ascertain the relative weight of these risk factors, but the composite picture enables the health worker to gauge a patient's risk for alcohol abuse.

Alcohol is classed as depressant because it produces sedation and sleep. However, the initial effects of alcohol particularly at low doses are often perceived as stimulation. The effects of alcohol include preoccupation with alcohol, anxiety, self-deception (denial), guilt, loss and impairment of memory, depression, etc. The alcohol withdrawal symptoms include alcohol craving, tremor, irritability, nausea, sleep disturbance [7].

KHAT

Khat is the leaves of and buds of an East African plan, cathaedulis, which are chewed or brewed as a beverage. It is a stimulant with effects similar to those of amphetamine. Heavy use can result in dependence and physical and mental problems resembling those produced by other stimulants [1].

Traditionally khat was used mainly among the Muslim populations. However, nowadays, many Christians especially the young also use it the prevalence rates of khat are different from place to place in Ethiopia. In a study conducted in Jimma Town in 2000, the prevalence of khat chewing was $30.6 \%$ out of which Muslims constituted $77.1 \%$. About twothirds of the khat chewers were males. In other similar studies, the prevalence rates of khat chewing in Butajira were $50 \%$. In a study conducted in 2001 among college students and instructors in Northwest Ethiopia, the lifetime prevalence rates of khat chewing were $26.7 \%$ and $42 \%$ respectively. In conclusion, the habit of khat chewing is believed to affect a large segment of the Ethiopian population, especially the productive age group. It has negative impact on health, socio economic and political matters. This is particularly true because the habit of khat chewing reinforces the development of other habits, such as cigarette smoking, alcohol intake and addiction with narcotics [8].

TOBACCO

A study done among Ethiopian university instructors in 2001 revealed a lifetime prevalence of $28.2 \%$ and current prevalence of $13.3 \%$. Studies have shown that the probability of dying from all causes is 2.3 times higher for current male smokers of cigarettes than males who are nonsmokers. These same studies indicate that the risk of dying from all causes is about two times higher for current female smokers compared to those females who do not smoke cigarettes.

Approximately $90 \%$ of individuals who become cigarette smokers initiate the behavior during adolescence. Factors that promote adolescent initiation are parental or older generation cigarette smoking, tobacco advertising 
and promotional activities, the availability of cigarettes, and the social acceptability of smoking. The level of acceptance of smoking in the home, peer group, workplace, and community norms influence smoking behavior. A number of studies have shown that nonsmoking women living with smoking spouses have a 1.2 to 2 times the risk of developing lung cancer during their lives than nonsmoking women in smoke-free homes [4].

Tobacco smoke contains noxious and cancer-producing ingredients. A long-term effect of tobacco is dependence (due to the substance nicotine it has) and other health ill effects such as bronchitis and coronary heart disease [9].

\section{Methodology}

This study is conducted at Debre Berhan town. Debre Berhan is fund 130 kilometers away from Addis Ababa which is the central city of Ethiopia. Participants of the study was drug user youths which are found in Debre Berhan town

Study variable

The dependent variable explored in this study is drug addiction (yes, no)

Independent variable;

The independent variables are causes for drug abuse are peer pressure, religion, accessibility of drug, previous history of family, employment status, income (monthly), age, sex, marital status, educational level

Chi-square test of independence

Chi-square test is used for determining whether there is any association or independent between two variables. It is based on the composition of the table of observed frequency and the expected frequency of two attributes which are independent

The model of chi-square can be written as;

$$
\chi^{2}=\sum_{i=1}^{k} \frac{\left(O_{i}-E_{i}\right)^{2}}{E_{i}}
$$

Where; $\mathrm{O}_{\mathrm{ij}}=$ observed values

$$
\mathrm{e}_{\mathrm{ij}}=\text { Expected values }
$$

The expectation of the certain category being in one economic group is written as;

$$
E=\frac{\text { row total } * \text { column total }}{\text { overall total }}
$$

The hypothesis to be tested is therefore,

Ho: the two attributes are independent or there is no significant association between the two attributes.

H1: the two attributes are dependent or there is significant association between the two attributes.

Where the attributes are the possible categorical variables used in the study.

Logistic Regression

The most popular model for binary data is logistic regression. It is used when the regressed, the dependent variable or the response variable is qualitative in nature or categorical. Qualitative response variable are either binary (dichotomous variable) or multiple category.

Binomial or binary logistic regression is the form of regression, which is used when the dependent variable is dichotomous, and the independent are of any type. Multinomial regression can handle the case of dependent variables with more than two classes.

Logistic regression can be used to predict a dependent variable on the basis of continuous and

Categorical independent variables to determine the percent of variance in the dependent variable explained by the independents, to rank the relative importance of independent variables to assess the interaction effect and to understand the impact of covariate control variables.

Logistic regression models are special cases of Generalized Linear Models $\left(\mathrm{GLM}_{\mathrm{s}}\right)$ for binary data. In logistic regression our objective is to find the probability of something happening (probability of success). It is used in various areas of social sciences and medical research.

For a binary response $\mathrm{y}$ and a quantitative explanatory variable $X$, let $\pi_{(\mathrm{x})}$ denote the success probability when $X$ takes value $\mathrm{X}$. This probability is the parameter for a binomial distribution. The logistic regression model has linear form for the legit of this probability [14],

$$
\begin{gathered}
\ln \left(\frac{\pi}{1-\pi}\right)=\beta_{o}+\beta_{1} \chi_{1}+\ldots+\beta_{k} \chi_{k} ; 0 \leq \pi \leq 1 \\
\pi=\frac{\exp \left(\beta_{o}+\beta_{1} \chi_{1}+\ldots+\beta_{k} \chi_{k}\right)}{1+\exp \left(\beta_{o}+\beta_{1} \chi_{1}+\ldots+\beta_{k} \chi_{k}\right)}
\end{gathered}
$$

Where, $\pi$ - the probability of success

$(1-\pi)$ - the probability of failure

$\beta_{0}$ - the constant term

$\beta_{\mathrm{i}}$ - coefficients of independent variables, for $\mathrm{i}=1,2,3, \ldots, \mathrm{k}$

$\mathrm{X}_{\mathrm{i}}$ - independent variables, for $\mathrm{i}=1,2,3, \ldots, \mathrm{k}$

1. The ratio of probability of success to probability of failure that is $[\mathrm{p} /(1-\mathrm{p})$ is odd ratio of success.

2. $\operatorname{Exp}(\beta \mathrm{j})$ where $\mathrm{j}=1,2 \ldots \mathrm{k}$ is a factor by which the odds of occurrence of success change by a unit increase in the $\mathrm{j}^{\text {th }}$ independent variables.

The Wald test: The Wald statistic is an alternative test which is commonly used to test the significance of individual logistic regression coefficients for each predictor variable (that is, to test the null hypothesis in logistic regression that a particular logit (effect) coefficient is zero). The Wald test statistic is: $\mathrm{W}=\left(\frac{\widehat{\beta}}{\operatorname{se}(\widehat{\beta})}\right)^{2}$

The Wald statistic, W, under the null hypothesis is approximately chi-square distributed. Each Wald statistic is compared with an $\mathrm{X}^{2}$ distribution with one degree of freedom. Wald statistics are easy to calculate but their reliability is questionable, particularly for small samples. For data that produce large estimates of the coefficient, the standard error is often inflated, resulting in a lower value of the Wald statistic, and therefore the explanatory variable may be incorrectly assumed to be unimportant in the model. Likelihood ratio tests are generally considered to be superior [15]. 


\section{Result and Discussion}

Table 1. Result of descriptive statistics.

\begin{tabular}{|c|c|c|c|c|c|}
\hline \multirow{3}{*}{ Variables } & \multirow{3}{*}{ Categories } & \multicolumn{4}{|c|}{ addiction of youth } \\
\hline & & \multicolumn{2}{|c|}{ yes } & \multicolumn{2}{|l|}{ No } \\
\hline & & Count & Row N\% & Count & Row N\% \\
\hline \multirow{2}{*}{ peer pressure } & Yes & 48 & $84.2 \%$ & 9 & $15.8 \%$ \\
\hline & No & 18 & $36.0 \%$ & 32 & $64.0 \%$ \\
\hline \multirow{2}{*}{ accessibility of drug } & easy to get & 60 & $80.0 \%$ & 15 & $20.0 \%$ \\
\hline & difficult to get & 6 & $18.8 \%$ & 26 & $81.2 \%$ \\
\hline previous history of family & Yes & 56 & $84.8 \%$ & 10 & $15.2 \%$ \\
\hline \multirow{4}{*}{ marital status } & Single & 48 & $69.6 \%$ & 21 & $30.4 \%$ \\
\hline & Married & 13 & $40.6 \%$ & 19 & $59.4 \%$ \\
\hline & Divorced & 4 & $80.0 \%$ & 1 & $20.0 \%$ \\
\hline & Widowed & 1 & $100.0 \%$ & 0 & $.0 \%$ \\
\hline \multirow{3}{*}{ Income } & $<400$ & 9 & $47.4 \%$ & 10 & $52.6 \%$ \\
\hline & $401-1000$ & 24 & $68.6 \%$ & 11 & $31.4 \%$ \\
\hline & $1001-2000$ & 13 & $56.5 \%$ & 10 & $43.5 \%$ \\
\hline \multirow{2}{*}{ Employment status } & Unemployed & 55 & $75.3 \%$ & 18 & $24.7 \%$ \\
\hline & Employed & 11 & $32.4 \%$ & 23 & $67.6 \%$ \\
\hline \multirow{4}{*}{ educational level } & primary school complete & 8 & $42.1 \%$ & 11 & $57.9 \%$ \\
\hline & secondary school complete & 13 & $81.2 \%$ & 3 & $18.8 \%$ \\
\hline & diploma and above & 22 & $62.9 \%$ & 13 & $37.1 \%$ \\
\hline & Student & 23 & $62.2 \%$ & 14 & $37.8 \%$ \\
\hline \multirow{4}{*}{ Religion } & Orthodox & 40 & $78.4 \%$ & 11 & $21.6 \%$ \\
\hline & Protestant & 8 & $23.5 \%$ & 26 & $76.5 \%$ \\
\hline & Muslim & 15 & $88.2 \%$ & 2 & $11.8 \%$ \\
\hline & Others & 3 & $60.0 \%$ & 2 & $40.0 \%$ \\
\hline \multirow{3}{*}{ Age } & $15-19$ & 13 & $48.1 \%$ & 14 & $51.9 \%$ \\
\hline & $20-25$ & 41 & $65.1 \%$ & 22 & $34.9 \%$ \\
\hline & $26-30$ & 12 & $70.6 \%$ & 5 & $29.4 \%$ \\
\hline \multirow{2}{*}{ Sex } & Male & 51 & $68.0 \%$ & 24 & $32.0 \%$ \\
\hline & Female & 15 & $46.9 \%$ & 17 & $53.1 \%$ \\
\hline
\end{tabular}

We can see in table 1 that out of 107 drugs user youth considered in the analysis 66 are addicted at the time of analysis.

1. Out of 75 male respondents $51(68 \%)$ are addicted to drug (yes) and 15 or 46.9 out of 32 female respondents are addicted to drug.

2. the result also shows 13 or $(48.1 \%)$ of respondents out of 27 respondents are addicted in age interval 15-19, 41 or $(65.1 \%)$ of respondents out of 63 respondents are addicted in age interval $20-25$, and 12 or $70.6 \%$ of respondents out of 17 respondents are addicted in age interval 26-30

3 . in case of religion out of 51 orthodox respondents 40 or $78.4 \%$ of respondents are addicted to drug, from 34 protestant respondents 8 or $23.5 \%$ of respondents are addicted to drug, out of 17 Muslim respondents 15 or $88.2 \%$ of respondents are addicted to drug and from 5 other religion (catholic....) follower 3 or $60 \%$ of the respondents are addicted to drug.

4. In case of educational level 8 or $42.1 \%$ of the respondents are addicted out of 11 primary school completed respondents, 13 or $81.2 \%$ addicted respondent out of 16 secondary school completed, 22 or $62.9 \%$ respondents are addicted out of 35 respondents whose education level are diploma and above, and out of 37 student respondents 23 or $62.2 \%$ of respondents are addicted to drug. By the same way we can interpret the others.

\section{INFERENTIAL STATISTICS}

Chi-Square

Table 2. Individual Chi square test for independent variable.

\begin{tabular}{llll}
\hline Independent variable & $\begin{array}{l}\text { Pearson } \\
\text { chi-square }\end{array}$ & df & $\begin{array}{l}\text { Asymp. sign.(2- } \\
\text { sided) }\end{array}$ \\
\hline Age & $4.235^{\mathrm{a}}$ & 1 & .040 \\
Sex & $2.971^{\mathrm{a}}$ & 2 & .226 \\
Religion & $32.070^{\mathrm{a}}$ & 3 & .000 \\
Educational level & $5.697^{\mathrm{a}}$ & 3 & .127 \\
Employment status & $18.138^{\mathrm{a}}$ & 1 & .000 \\
Income & $2.924^{\mathrm{a}}$ & 3 & .403 \\
Marital status & $9.149^{\mathrm{a}}$ & 3 & .027 \\
Previous history of family & $39.111^{\mathrm{a}}$ & 1 & .000 \\
Accessibility of drug & $35.602^{\mathrm{a}}$ & 1 & .000 \\
Peer pressure & $26.193^{\mathrm{a}}$ & 1 & .000 \\
\hline
\end{tabular}

from the above test (Chi-square test of independency), seven variables namely age, religion, unemployment marital status, previous history of family, accessibility of drug peer pressure are the candidate variables for our binary logistic regression model due to their association with the dependent variable addiction of youth. From the above table the remaining factors are insignificant (it is not necessary factors to fit the good models). 
Table 3. Result of binary logistic regression.

\begin{tabular}{|c|c|c|c|c|c|c|c|c|c|}
\hline \multicolumn{10}{|c|}{ Variables in the Equation } \\
\hline & & \multirow{2}{*}{ B } & \multirow{2}{*}{ S. E. } & \multirow{2}{*}{ Wald } & \multirow{2}{*}{ df } & \multirow{2}{*}{ Sig. } & \multirow{2}{*}{$\operatorname{Exp}(B)$} & \multicolumn{2}{|c|}{$95.0 \%$ C. I. for EXP (B) } \\
\hline & & & & & & & & Lower & Upper \\
\hline \multirow{39}{*}{ Step $1^{\mathrm{a}}$} & Sex & -1.121 & 1.274 & .775 & 1 & .379 & .326 & .027 & 3.958 \\
\hline & male & & & & & & & & \\
\hline & Female (ref) & & & & & & & & \\
\hline & Age & & & 4.409 & 2 & .110 & & & \\
\hline & $15-19$ & .247 & 1.812 & .019 & 1 & .892 & 1.280 & .037 & 44.655 \\
\hline & $20-25$ & -3.129 & 1.760 & 3.163 & 1 & .075 & .044 & .001 & 1.376 \\
\hline & $26-30$ (ref) & & & & & & & & \\
\hline & Religion & & & 8.981 & 3 & .030 & & & \\
\hline & Orthodox & .136 & 2.953 & .002 & 1 & .963 & 1.146 & .004 & $3.737 \mathrm{E} 2$ \\
\hline & Protestant & 5.803 & 3.324 & 3.048 & 1 & .008 & 331.228 & .491 & $2.236 \mathrm{E} 5$ \\
\hline & Muslim & -1.689 & 3.232 & .273 & 1 & .601 & .185 & .000 & $1.041 \mathrm{E} 2$ \\
\hline & Others (ref) & & & & & & & & \\
\hline & Educationallevel & & & 3.830 & 3 & .280 & & & \\
\hline & Primary school complete & -.518 & 1.938 & .071 & 1 & .789 & .596 & .013 & 26.609 \\
\hline & Secondary school complete & -6.189 & 3.203 & 3.734 & 1 & .053 & .002 & .000 & 1.092 \\
\hline & Diploma and above & -.822 & 1.547 & .282 & 1 & .595 & .439 & .021 & 9.117 \\
\hline & Student (ref) & & & & & & & & \\
\hline & Employment status & & & & & & & & \\
\hline & Unemployed & -4.631 & 2.026 & 5.225 & 1 & .022 & .010 & .001 & .517 \\
\hline & Employed (ref) & & & & & & & & \\
\hline & Income & & & 4.107 & 3 & .250 & & & \\
\hline & $<400$ & -2.028 & 2.018 & 1.010 & 1 & .315 & .132 & .003 & 6.871 \\
\hline & $400-1000$ & -2.907 & 2.007 & 2.098 & 1 & .148 & .055 & .001 & 2.792 \\
\hline & $1001-2000$ & .448 & 1.890 & .056 & 1 & .812 & 1.566 & .039 & 63.591 \\
\hline & $>2000$ (ref) & & & & & & & & \\
\hline & Marital status & & & 5.349 & 3 & .148 & & & \\
\hline & Single & 23.262 & $4.019 \mathrm{E} 4$ & .000 & 1 & 1.000 & $1.267 \mathrm{E} 10$ & .000 & . \\
\hline & Married & 20.854 & $4.019 \mathrm{E} 4$ & .000 & 1 & 1.000 & $1.140 \mathrm{E} 9$ & .000 & . \\
\hline & Divorced & 17.168 & $4.019 \mathrm{E} 4$ & .000 & 1 & 1.000 & $2.859 \mathrm{E} 7$ & .000 & . \\
\hline & Widowed (ref) & & & & & & & & \\
\hline & Previous history of family & & & & & & & & \\
\hline & Yes & 3.032 & 1.379 & 4.832 & 1 & .028 & 20.739 & .003 & .720 \\
\hline & No (ref) & & & & & & & & \\
\hline & Accessibility of drug & & & & & & & & \\
\hline & Easy to get & 3.015 & 1.524 & 3.911 & 1 & .048 & 20.389 & .002 & .973 \\
\hline & Difficult to get (ref) & & & & & & & & \\
\hline & Peer pressure & & & & & & & & \\
\hline & $\begin{array}{l}\text { Yes } \\
\text { no (ref) }\end{array}$ & -3.956 & 1.872 & 4.465 & 1 & .035 & .019 & .00 & .751 \\
\hline & Constant & -10.546 & $4.019 \mathrm{E} 4$ & .000 & 1 & 1.000 & .000 & & \\
\hline
\end{tabular}

Previous history of family of the respondent categorized as yes and no (reference group. The result in the Table shows that whose family member user drug is about 20.739 (coeff. 3.032, $\mathrm{OR}=20.739$, CI: $0.003-0.720$ ) times more likely addicted to drug than the reference group (those whose family member doesn't use drug).

Accessibility of drug is categorized as easy to get and difficult to get (reference group). The result in the Table shows that participants who access drug easily are about 20.389 (coeff. 3.089, OR=20.389, CI: 0.002-0.973) times more likely addicted to drug than the reference group (those who are difficult to get).

Peer pressure is categorized as yes (there peer pressure) and no (reference group) the result in the Table shows that the odds of participants who are influenced by peer pressure are about 0.019 (coeff. $-3.956, \mathrm{OR}=0.019$, CI: 0.01-0.751) Times less likely addicted to drug than the reference group (those who are not forced by peer pressure).

\section{Conclusion}

Based on the result of this paper we can conclude that the numbers of youth those are addicted in the age group 20-25 are much greater than from the youth those are addicted in the age group 15-19 and 25-30, youths with family members who use drugs are more likely to be drug addicts, and also those who are orthodox religion followers are more likely to be addicted than Muslim, protestant and other religion follower, additionaly youth who are single are more drug user than married, divorced and widowed.

The binary logistic model identified five variables which is significantly factor for addiction of youth in debre berhan town. These are: religion, employment status, previous history of family, accessibility of drug and peer pressure. 


\section{References}

[1] United Nations Office on Drugs and Crime. Treatnet: International network of drug dependence treatment and rehabilitation resource centres. Vienna, UNODC, 2008.

[2] United Nations Office on Drugs and Crime. Treatnet: International network of drug dependence treatment and rehabilitation resource centres. Vienna, UNODC, 2014.

[3] Gorski and Miller (2015), A guide for relapse prevention, US Independence press, Sep 4, 2015

[4] Doweiko E. Harold (2011). Concepts of Chemical Dependency (7th ed.), Cole publishingcompany, USA.

[5] United Nations (2011), the United Nations and Drug Abuse Control. UN Publication, Vienna.

[6] World Health Organization. Evidence for action: effectiveness of drug dependence treatment. Geneva, WHO, 2014.

[7] Yigzaw Kebede, Tefera Abula, Belete Ayele, Amsalu Feleke, Getu Degu, Abera Kifle, Zeleke Alebachew, Endris Mekonnen, and Belay Tessema (2013), Substance Abuse; University of Gondar, Ethiopia.

[8] Mulugeta Assefa (2015). Socio-economic aspects of khat:
Proceedings of International Conference on khat. Antananarivo, January 17-21, Madagascar Santrock. Life Span Development (7th ed),. Boston: MCGRAW Hill Companies, Inc.

[9] University of Gondar (2013), Module on Substance Abuse for the Ethiopian Health Center team, Master printing, Addis Ababa.

[10] American Psychiatric Association (2016), Diagnostic and Statistical Manual of Mental Disorder, USA.

[11] DACA (2011), National Drug Control Master Plan of 20102014. Addis Ababa: CommercialPrinting Enterprise, Ethiopia.

[12] Daniel L. Yalisove (2017), Essential Papers on Addiction, New York University press, USA Running Head: Exploring the Trends \& Challenges of Substance Abuse.

[13] Wallace, M. John and Muroff, R. Jordan. (2002). Preventing Substance Abuse Among African Childern and Youth: Race differences and Risk factor Exposure and Vulnerability. The Journal of Primary Prevention Vol 22 No. 3.

[14] Agresti, A. (2002), Categorical Data Analysis. Wiley Interscience, New York.

[15] Hosmer, W. D. and S. Lemeshow (2000), Applied Logistic Regression. 2nd Edn., John Wiley and Sons, New York. 